\title{
Sexuality of Young Adults with Cerebral Palsy: Experienced Limitations and Needs
}

\author{
Diana Wiegerink • Marij Roebroeck • Jim Bender • Henk Stam • \\ Peggy Cohen-Kettenis • Transition Research Group South West Netherlands
}

Published online: 12 October 2010

(C) The Author(s) 2010. This article is published with open access at Springerlink.com

\begin{abstract}
Objective of this study is to describe the problems young adults with Cerebral Palsy (CP) experience in the various stages of the sexual response cycle, and the physical and emotional obstacles they experience with sexuality. In this prospective cohort study 74 young adults (46 men; 28 women) with CP and average intelligence participated, aged 20-24 years. Twenty percent of these young adults with CP experienced anorgasmia, $80 \%$ reported physical problems with sex related to $\mathrm{CP}$ and $45 \%$ emotional inhibition to initiate sexual contact. In $90 \%$ of the participants, sexuality had not been discussed during the rehabilitation treatment. Many adolescents reported wanting information about the impact of CP on sexuality and reproduction (35\%), about interventions (26\%), tools and medicines $(16 \%)$ and about problems with their partner (14\%). Young adults with CP can experience various problems or challenges with sexuality. For preventing sexual difficulties and treating sexual problems, health care professionals need to proactively take the initiative to inform young people with $\mathrm{CP}$ about sexuality.
\end{abstract}

Keywords Cerebral palsy $\cdot$ Sexuality $\cdot$ Young adults $\cdot$ The Netherlands

D. Wiegerink $(\varangle) \cdot$ M. Roebroeck $\cdot$ H. Stam

Department of Rehabilitation Medicine and Physiotherapy, Erasmus MC, Rotterdam, The Netherlands

e-mail: d.wiegerink@erasmusmc.nl

D. Wiegerink

Rijndam Rehabilitation Center, Rotterdam, The Netherlands

J. Bender

Sophia Rehabilitation Center, The Hague, The Netherlands

P. Cohen-Kettenis

Department of Medical Psychology and Medical Social Work, VU University Medical Center, Amsterdam, The Netherlands 


\section{Introduction}

Cerebral palsy (CP) is defined as a group of permanent disorders in the development of posture and movement which cause limitations in activities, and is attributed to nonprogressive disturbances that occur in the developing brains of a fetus or baby [1]. Posture and movement disorders in $\mathrm{CP}$ are often accompanied by disturbances in perception, cognition, communication and behavior, as well as by epilepsy [1]. Cerebral Palsy (CP) is the most common cause of physical disability in childhood with a prevalence of 1.5-2.5 per 1000 live births [2, 3].

Through improved medical care, many young people with a congenital disability now reach adulthood. Even after the transition to adulthood this group still requires care. The importance of "life-span care" is receiving increasing attention [4, 5].

The transition from adolescence to adulthood is a normal developmental phase in which young people become independent in many areas of life. Key areas are: the transition from school to work, independent living, development of personal financial responsibility, forming intimate relationships and developing sexual identity, and organizing independent transportation [6]. During this period, the focus of young people shifts away from familycentered activities giving more attention and interest to their circle of friends. For young people with physical disabilities or chronic illness, this phase can be extra difficult. Like others of their age, they have many new skills to learn. In addition they need to learn how to cope with their limitations in new social situations, such as at work and in intimate relationships [7].

The period between 12 and 25 years of age is essential for human sexual development: physical changes, masturbation, dating, beginning intimate relationships and sexual experiences. This applies to people with and without physical disabilities or chronic illnesses.

Lock [8] in his literature review of young people with physical disabilities notes three developmental stages of adolescence; each of these phases can bring about specific problems related to relationships and sexuality. In the early phase (11-13 years), adolescents are concerned about physical (pubescent) development, such as secondary sex characteristics development and a different outward appearance. In the middle stage (14-16 years), the contacts with peers become central. Especially in peer groups, there is a lot to learn and share when it comes to dating and sexual experiences. Research focusing on young adults with CP shows that a peer group is conducive to going out together and engaging in dating activities [9]. In the final stage (17-19 years), developing long-term intimate relationships becomes central and with that, questions about fertility and genetics become more prominent. Dependence on parents can make it difficult for some young people to develop the adult roles that are important for building a relationship necessary for experiencing intimacy. Also, the undesirability that they will be dependent on a potential partner for their personal care worries young adults with physical disabilities. Investigations into the sexual experience of young people with physical limitations show very divergent results. Some American and Spanish studies [10-12] indicated that these young people had as much experience with sexual contact and sexual intercourse as their peers without disabilities. A recent Swedish study [13] indicated that young people with physical disabilities had, relatively speaking, much experience with intercourse. The young people in this study, however, were very diverse in the kinds of disabilities. Dutch studies in adolescents and young adults with spina bifida [14] and CP [15] have shown a different picture: they have less experience with all the steps of sexual development when compared to age appropriate references. From a previous study we know that young adults with CP (18-22 years) were significantly less experienced with dating (77\%) than their 
non-disabled peers (89\%). At the time of this survey among young people with $\mathrm{CP}$, only a few of them had a current romantic relationship (23\% versus $61 \%$ of Dutch peers) [9]. Many young people with CP start later than other Dutch young people with their first kiss and sexual debut (intercourse): on average, 16.3 versus 14 years of age and 18.4 versus 16.7 years of age $[16,17]$.

In their development of intimate relationships and sexuality young people with $\mathrm{CP}$ are confronted with physical limitations. Pubescent physical development in children with CP is known to start earlier and end later than children without CP [18]. Yet, little is known about the sexual functions and the physical problems these young adults can experience with sex.

The aim of the present study was to describe sexual experience and sexual response cycle functioning, physical and emotional problems regarding sexuality, and information needs of young adults with CP. By enhancing our understanding of the physical and emotional problems that may influence the formation of intimate and sexual relationships in young adults with $\mathrm{CP}$ we hope to contribute to improved multidisciplinary care for this group.

\section{Method}

\section{Participants}

In the CP Transition study, we followed 103 young people (62 men, 41 women) within the average range for intellectual functioning and aged 16-20 years, for four years, focusing on various aspects of social participation, including the development of intimate and sexual relationships $[6,15,19]$. The CP Transition Study is part of the Pediatric Rehabilitation Research in the Netherlands (PERRIN) program (http://www.perrin.nl). The Medical Ethics Committee of Erasmus MC Rotterdam approved this study. All participants provided verbal and written informed consent to participate. Participants were recruited from eight rehabilitation centers and departments in the Southwestern regions of the Netherlands. Inclusion criteria were a diagnosis of CP and an age between 16-20 years (birth year 1982-1986). Exclusion criteria were the existence of cognitive disabilities (IQ below 70), co-morbidity with a persistent effect on motor functioning, and inadequate proficiency with the Dutch language. Of 437 potential subjects, $35 \%$ were excluded because of cognitive disabilities and $18 \%$ were lost due to incorrect addresses. An information letter about the study was sent to 184 patients, and 103 participated (response rate 56\%). At four-year follow-up, 74 young adults (20-24 years) participated (see Table 1). The results of this latter measurement will be presented here.

Demographic data for gender, age and education level were collected (Table 1). We distinguished three levels of education: (1) low: pre-vocational practical education or less (special education for IQ 70-85); (2) medium: pre-vocational theoretical education and upper secondary vocational education (vocational high school); and (3) high: secondary education, post-secondary college and/or university level education (preparatory high school and high school).

Gross motor functioning was classified with the Gross Motor Functioning Classification System (GMFCS) [20], a 5-level classification system for assessing severity of gross motor limitations [20, 21]. Manual ability was classified with the Manual Ability Classification System (MACS), a system designed to classify how children with CP use their hands when handling objects during daily activities, which is also valid for young adults with CP $[19,22]$. Trained physiotherapists (AdG and EC) conducted the GMFCS and MACS assessments and examined paresis distribution (49\% unilateral) and CP type (94\% spastic). 
Table 1 Characteristics of the participants

\begin{tabular}{|c|c|c|c|c|}
\hline Characteristics & $N$ & & $N$ & $\%$ \\
\hline \multirow[t]{2}{*}{ Gender } & \multirow[t]{2}{*}{74} & Men & 46 & 62 \\
\hline & & Women & 28 & 38 \\
\hline \multirow[t]{6}{*}{ Age (years) } & \multirow[t]{6}{*}{74} & 20 & 7 & 10 \\
\hline & & 21 & 17 & 23 \\
\hline & & 22 & 12 & 16 \\
\hline & & 23 & 21 & 28 \\
\hline & & 24 & 12 & 16 \\
\hline & & 25 & 5 & 7 \\
\hline \multirow[t]{3}{*}{ Educational level } & \multirow[t]{3}{*}{72} & Low & 14 & 20 \\
\hline & & Middle & 29 & 40 \\
\hline & & High & 29 & 40 \\
\hline \multirow[t]{2}{*}{ Laterality } & \multirow[t]{2}{*}{74} & Uni & 36 & 49 \\
\hline & & $\mathrm{Bi}$ & 38 & 51 \\
\hline \multirow[t]{5}{*}{ GMFCS } & \multirow[t]{5}{*}{74} & I & 56 & 76 \\
\hline & & II & 6 & 8 \\
\hline & & III & 4 & 5 \\
\hline & & IV & 7 & 10 \\
\hline & & V & 1 & 1 \\
\hline \multirow[t]{5}{*}{ MACS } & \multirow[t]{5}{*}{73} & I & 62 & 85 \\
\hline & & II & 8 & 11 \\
\hline & & III & 2 & 3 \\
\hline & & IV & - & - \\
\hline & & $\mathrm{V}$ & 1 & 1 \\
\hline \multirow[t]{3}{*}{ Speech } & \multirow[t]{3}{*}{74} & Audible & 67 & 91 \\
\hline & & Audible, although disturbed & 6 & 8 \\
\hline & & Disturbed, not audible & 1 & 1 \\
\hline
\end{tabular}

Questionnaires

Using a self-developed written questionnaire, participants were extensively asked about sexual experiences such as masturbation and the sexual milestones French kissing, caressing under clothes, cuddling nude and intercourse. Based on the classification of aspects of the sexual response cycle by Masters and Johnson, and complemented by Kaplan [21], young adults with CP were asked how they functioned in terms of the following aspects: seeking sexual stimulation (seeking out erotic images, sexual fantasies), having sexual desires (do you ever think about what it is like having sex, how you would like to have sex), experiencing sexual arousal, and having an orgasm. For these topics we have used questions from the survey "Sex under the age of 25" [16]. For CP-related experiences and problems with sex we used questions from the survey "Does rehabilitation also include sex?" [23].

\section{Statistical Analysis}

The results for men and women are shown separately and were tested with a Pearson Chisquare test. Answers about the sexual response cycle were dichotomized as yes (very often, 
often, regularly, sometimes) and no (almost never, never). Responses to perceived problems were dichotomized as yes (a lot, quite a bit, not a little/not a lot, little effect on sex) and no (no effect on sex). For the statistics, we made use of SPSS 16.0.

Not all the participants had experience with all the sexual issues discussed. This led to a variance in the number of participants per question.

\section{Results}

Participants

The mean age of the participants was 22 years and 8 months. The total of the cohort can be characterized as mainly having a spastic parese, a relatively high level of gross motor functioning and manual ability, good audibility and normal cognitive functioning (see Table 1).

\section{Sexual Experiences}

Seventy-six percent of the participants had experience with masturbation. Most young adults with $\mathrm{CP}$ had reached one or more sexual milestones; $78 \%$ had experience with French kissing, 70\% with caressing under clothing, 65\% with cuddling nude and 54\% with sexual intercourse. Twenty percent had no sexual experience with a partner.

\section{Sexual Functioning}

Significantly more men (50\%) than women (7\%) sought out erotic pictures of the opposite sex or fantasized about them (respectively $86 \%$ and $56 \%$ ). Many $(78 \%$ ) reported experiencing feelings of sexual arousal, and two-thirds of the group had experienced an orgasm. (see Table 2).

\section{Problems with Sex}

\section{Physical Problems}

There was a wide variation in the physical problems with sex experienced by young adults with $\mathrm{CP}$, and in the frequency of the problems reported: from spasticity (41\%) to urinary incontinence, paralysis or numbness (5\%) (see Table 3 ). These problems may limit young adults in terms of positions and postures during sexual activities: "It's all less flexible." In addition, they had less persistence, it took them more time than their partner or they became tired too soon. Also, restricted manual ability was mentioned by the participants as an obstacle. Young adults were not always able to specify concretely how they experienced an obstacle; "It's just more difficult" is how it was put. The problems experienced did not always lead to obstacles in having sex; $20 \%$ indicated they experienced no obstacles due to physical limitations.

Some young adults (6\%) indicated that they depended on the assistance of others in preparing for sex (such as being put on a bed). It seemed that some had not found a solution for this, as was apparent from answers such as "I don't do it" or "no experience." Possibly no partner was available. 
Table 2 Sexual functioning in young adults with CP

\begin{tabular}{|c|c|c|c|c|}
\hline$(N=68)$ & $\begin{array}{l}\text { Men } \\
\%\end{array}$ & $\begin{array}{l}\text { Women } \\
\%\end{array}$ & $\begin{array}{l}\text { Difference men- } \\
\text { women }\left(\mathrm{Chi}^{2}\right)\end{array}$ & $p$ \\
\hline \multicolumn{5}{|l|}{ Seeking sexual stimuli: } \\
\hline Looking for erotic pictures, photos, stories, movies & 50 & 7 & 19.99 & .001 \\
\hline Sexual fantasies about men & 9 & 56 & 28.03 & $<.001$ \\
\hline Sexual fantasies about women & 86 & 16 & 34.89 & $<.001$ \\
\hline \multicolumn{5}{|l|}{ Sexual desire: } \\
\hline Do you ever think about what it's like to have sex? & 94 & 69 & 13.52 & .01 \\
\hline $\begin{array}{l}\text { How would you like to have sex with someone (on a } \\
\text { scale from } 1 \text { to } 10: \geq 7 \text { )* }\end{array}$ & 58 & 40 & 14.60 & .10 \\
\hline $\begin{array}{l}\text { Arousal experienced during sexual intercourse or } \\
\text { masturbation }\end{array}$ & 74 & 84 & 9.98 & .08 \\
\hline $\begin{array}{l}\text { Orgasm during sexual intercourse or masturbation } \\
\text { (regularly, often, always) }\end{array}$ & 67 & 64 & 11.07 & .09 \\
\hline
\end{tabular}

Bold $p$ values indicate significant differences

* This question answered by only 24 people (19 men, 5 women)

Table 3 Top 10 of the physical obstacles most cited by young adults with CP in having sex

\begin{tabular}{|c|c|c|c|c|}
\hline & \multirow[t]{2}{*}{ Bothered by: } & \multicolumn{3}{|c|}{$\%$ of young adults experiencing problems } \\
\hline & & $\begin{array}{l}\text { Total group } \\
N=59\end{array}$ & $\begin{array}{l}\text { Men } \\
N=38\end{array}$ & $\begin{array}{l}\text { Women } \\
N=21\end{array}$ \\
\hline 1. & Spasticity & 41 & 34 & 52 \\
\hline 2. & Difficulty spreading legs & 31 & 31 & 33 \\
\hline 3. & Difficulties with pelvic tilt & 29 & 29 & 29 \\
\hline 4. & Stiffness of joints and muscles & 28 & 19 & 43 \\
\hline 5. & Fatigue* & 25 & 14 & 43 \\
\hline 6. & Balance problems & 22 & 11 & 38 \\
\hline 7. & Impaired manual ability & 20 & 17 & 25 \\
\hline $8 / 9$ & Lack of energy* & 18 & 8 & 35 \\
\hline $8 / 9$ & Loss of strength & 18 & 14 & 25 \\
\hline 10. & Trembling & 13 & 17 & 5 \\
\hline
\end{tabular}

* Women experience significantly more problems here than men, respectively $p=0.02$ (fatigue) and $p=0.05$ (lack of energy)

\section{Emotional Problems}

More than half $(55 \%)$ of young adults with CP reported no emotional limitations when it came to sexuality, while $19 \%$ said they lacked self-confidence. The term shame was also used; being ashamed of one's own body (15\%) or of its limitations (11\%) came up, while $9 \%$ experienced their scars as a hindrance.

With CP, the body has often been approached in a very functional way (for example, by doctors, nurses, caregivers, physiotherapists). One consequence of this is that $20 \%$ experienced their body differently from people without disabilities. Remarks made in this vein were: "I keep people at a distance," "Because I need help from caregivers, I cannot have 
sex in an uninhibited way," "I am almost always aware of the limitations I have" and "I have to concentrate on actions other people never have to think about."

\section{Positive Effects from Sexuality on Physical Complaints}

Having sex (not specified in greater detail) could also have beneficial effects on spasticity or stiffness; relaxation was an especially positive effect (12\%).

\section{Information Needs}

From the first measurement [15] we know that nearly all respondents had received sex education about reproduction, birth control and sexual transmitted diseases. School (99\%) and parents $(63 \%)$ appeared to be important sources of information whereas literature (42\%), radio-television (40\%), and peers (37\%) also contributed to their knowledge. Sixty percent of the boys and $88 \%$ of the girls had received information about sexual harassment, but only $14 \%$ had received specific information on disability and sexuality.

Although many young people (59\%) at the time of the trial had no contact with a rehabilitation specialist, most had had some in the past [6]. When asked whether the subject of sexuality had come up in rehabilitation, $90 \%$ said that it had not. Yet there are many issues regarding sexuality that young adults with $\mathrm{CP}$ would like information about: $35 \%$ about the impact of CP on sexuality and fertility, 26\% about treatment options, $16 \%$ (medical) devices and medicines, and 14\% would like to discuss sexual problems they had with a partner.

\section{Discussion}

We found differences between men and women with $\mathrm{CP}$ in seeking sexually stimulating pictures and desire for sex, which are consistent with differences between men and women without physical disabilities known from the literature: men have more sexual fantasies and think more about sex, whereas women are sensitive to a broader range of sexual stimuli [24]. The differences in fantasizing about sexual partners were as expected; most women fantasize about men and most men fantasize about women.

A fairly large portion (one-fifth) of the participants did not have orgasms. This appears to be more prevalent in young adult men with CP than in Dutch men (5\% of Dutch men have regular or frequent problems with orgasm). In women with $\mathrm{CP}$, however, orgasm problems appear to be less common than in Dutch women (27\% of Dutch women have regular or frequent problems with orgasm). Maybe the context of reference for women with CP differs from that of the Dutch age mates: quantifications as 'sometimes' or 'regularly' may have a different meaning related to the frequency of experience. If women with $\mathrm{CP}$ were less frequently experienced with orgasm compared to Dutch age mates, their context of terms as 'sometimes' or 'regularly' may be different. What is 'regularly' for women with CP may be 'sometimes' for the Dutch references. Anorgasmia does not necessarily indicate a dysfunction; therefore the difficulties had to be experienced as a problem.

Although three quarter of the group was functioning on the highest level of the GMFCS, many participants reported physical obstacles in having sex. This implies that they, notwithstanding few restrictions in gross motor functioning, still experience physical limitations with sex. The reported physical problems were diverse. It is notable that women 
significantly more than men reported to experience problems with energy and fatigue. However, in the study by Jahnsen no difference was found for fatigue between men and women with CP [25]. Patterns of response to sexual desire and sexual arousal differ between men and women; men more easily permit sexual arousal and experience positive emotions [24]. This can implicate that for men the drive of having sex is more important than their lack of energy. Otherwise women react more cautious. In that case lack of energy and fatigue are more prominent experienced as limitations for having sex.

Lack of confidence and uncertainty often play a role in the first sexual experiences for many young people without physical disabilities [26]. However, young adults with CP have extra hurdles to overcome: developing a positive relationship with their bodies, learning to deal with their own physical limitations, possibilities and needs regarding sex, and being able and daring to discuss all this with a partner. This calls for a challenging need of skills and confidence on their part, especially considering that they are at the beginning of their sexual career.

Also notable is the reported shame about their bodies and the psychological barrier that scars can represent. This can mean that, as a result, young adults with $\mathrm{CP}$ had a positive image of their appearance (with clothes), but they can have a negative body image (the naked body).

It is clear that many young adults with CP need support with their problems with sex. This involves help with physical aspects such as spasticity and restricted manual ability, on the one hand. On the other hand, it also involves psychological support for acceptance of their physical and sexual self-image, as well as learning to discuss limitations and opportunities with a partner. In addition, information on aspects of reproduction and genetics is needed.

Despite the perceived problems and the need for information, it is striking that sexuality rarely comes up as a topic of discussion in the rehabilitation of young adults. In pediatric rehabilitation, sexuality is not a subject that is discussed with parents by health care professionals. The physical constraints are paramount, followed by behavioral and learning issues. This is partly due to parents' unawareness that their disabled child is also a sexual being. They often do not realize that developing a positive body image is important, or that they should provide space for the sexual feelings of their child.

Because many young people with relatively mild disabilities leave pediatric rehabilitation at an early age, sexuality has commonly not been a topic of discussion for professionals, parents and youngsters. During the transition phase, young people have to learn to understand their bodies, their illness and limitations, and they also need to learn to request help. In addition, in this phase it becomes increasingly important for the young person to be able to speak without his parents about sexuality. Sexuality is a subject that many young people do not easily talk about in the presence of their parents, especially if parents also do not feel comfortable discussing the topic.

As so many people find it difficult to discuss sexuality, it is the responsibility of the professional to raise this issue. Our research clearly shows that a significant number of young adults with $\mathrm{CP}$ experience problems with sexuality, and that they need help and diagnosis-specific information. In adult rehabilitation, professionals usually are faced with the consequences of the recent onset of disease. In contrast, CP is a congenital disability. Problems with sex should thus be seen more from a developmental perspective. Developing intimate relationships and exploring sexuality are central, instead of changes in sexuality. People with CP are developing sexually at an older age [17] and are consequently confronted with sexual problems later. 


\section{Conclusion}

A significant number of young adults with $\mathrm{CP}$ experiences both physical and emotional problems with sex. They need diagnosis-specific information and may need assistance discussing sexual issues with their partner. Rehabilitation professionals need to take the initiative during their regular contact to discuss potential problems with sex that young adults with $\mathrm{CP}$ might encounter.

Acknowledgments The authors wish to thank all the participating young adults with CP. The following members of the Transition Research Group South West Netherlands contributed to this study: Department of Rehabilitation Medicine, Erasmus MC, University Medical Center, Rotterdam, (M Donkervoort PhD, C Nieuwenhuijsen MSc, J van Meeteren MD PhD); Rijndam Rehabilitation Center, Rotterdam (MP Bergen MD PhD, HJR Buijs MD); Sophia Rehabilitation Center, The Hague (W Nieuwstraten MD †, A de Grund PT)/Delft (M Terburg MD, E Celen PT); Rijnlands Rehabilitation Center, Leiden (H vd Heijden-Maessen MD); Foundation of Rehabilitation Medicine Zeeland, Goes (Th Voogt MSc); Department of Rehabilitation Medicine, Leiden University Medical Center (JH Arendzen MD PhD, MS van Wijlen-Hempel MD PhD). In addition the Rehabilitation Center De Hoogstraat, Utrecht co-operated. This research was conducted as part of the PERRIN (Pediatric Rehabilitation Research in the Netherlands) research program. With financial support from the Johanna Children's Fund, Children's Fund Adriaanstichting, (JKF Number 07.02.28-2007/ 0042) and from the Fund for Scientific Research on Sexuality.

Open Access This article is distributed under the terms of the Creative Commons Attribution Noncommercial License which permits any noncommercial use, distribution, and reproduction in any medium, provided the original author(s) and source are credited.

\section{References}

1. Rosenbaum, P., Paneth, N., Leviton, A., Goldstein, M., Bax, M., Damiano, D., et al.: A report: the definition and classification of cerebral palsy April 2006. Dev. Med. Child. Neurol. Suppl. 109, 8-14 (2007)

2. Mutch, L., Alberman, E., Hagberg, B., Kodama, K., Perat, M.V.: Cerebral palsy epidemiology: where are we now and where are we going? Dev. Med. Child. Neurol. 34(6), 547-551 (1992)

3. Paneth, N., Hong, T., Korzeniewski, S.: The descriptive epidemiology of cerebral palsy. Clin. Perinatol. 33(2), 251-267 (2006)

4. Roebroeck, M.E., Jahnsen, R., Carona, C., Kent, R.M., Chamberlain, M.A.: Adult outcomes and lifespan issues for people with childhood-onset physical disability. Dev. Med. Child. Neurol. 51(8), 670-678 (2009)

5. Hilberink, S.R., Roebroeck, M.E., Nieuwstraten, W., Jalink, L., Verheijden, J.M., Stam, H.J.: Health issues in young adults with cerebral palsy: towards a life-span perspective. J. Rehabil. Med. 39(8), 605-611 (2007)

6. Donkervoort, M., Wiegerink, D.J., van Meeteren, J., Stam, H.J., Roebroeck, M.E.: Transition to adulthood: validation of the rotterdam transition profile for young adults with cerebral palsy and normal intelligence. Dev. Med. Child Neurol. 51(1), 53-62 (2009)

7. McDonagh, J.E.: Transition of care from paediatric to adult rheumatology. Arch. Dis. Child. 92(9), 802-807 (2007)

8. Lock, J.: Psychosexual development in adolescents with chronic medical illnesses. Psychosomatics 39(4), 340-349 (1998)

9. Wiegerink, D.J., Roebroeck, M.E., VDS, W.M., Stam, H.J., Cohen-Kettenis, P.T.: Importance of peers and dating in the development of romantic relationships and sexual activity of young adults with cerebral palsy. Dev. Med. Child. Neurol. 52(6), 576-582 (2010)

10. Suris, J.C., Resnick, M.D., Cassuto, N., Blum, R.W.: Sexual behavior of adolescents with chronic disease and disability. J. Adolesc. Health 19(2), 124-131 (1996)

11. Suris, J.C., Parera, N.: Sex, drugs and chronic illness: health behaviours among chronically ill youth. Eur. J. Public. Health 15(5), 484-488 (2005)

12. Cheng, M.M., Udry, J.R.: Sexual behaviors of physically disabled adolescents in the United States. J. Adolesc. Health. 31(1), 48-58 (2002) 
13. Brunnberg, E., Boström, M.L., Berglund, M.: Sexuality of 15/16-year-old girls and boys with and without modest disabilities. Sex Disabil (2009)

14. Verhoef, M., Barf, H.A., Vroege, J.A., Post, M.W., Van Asbeck, F.W., Gooskens, R.H., et al.: Sex education, relationships, and sexuality in young adults with spina bifida. Arch. Phys. Med. Rehabil. 86(5), 979-987 (2005)

15. Wiegerink, D.J., Roebroeck, M.E., Donkervoort, M., Cohen-Kettenis, P.T., Stam, H.J.: Social, intimate and sexual relationships of adolescents with cerebral palsy compared with able-bodied age-mates. J. Rehabil. Med. 40(2), 112-118 (2008)

16. de Graaf, H., Meijer, S., Poelman, J., Vanwesenbeeck, I.: Seks onder je 25e. Seksuele gezondheid van jongeren in Nederland anno 2005. Delft, Eburon (2005)

17. Wiegerink, D.J., Stam, H.J., Gorter, J.W., Cohen-Kettenis, P.T., Roebroeck, M.E.: Development of romantic relationships and sexual activity in young adults with cerebral palsy: a longitudinal study. Arch. Phys. Med. Rehabil. 91(9), 1423-1428 (2010)

18. Worley, G., Houlihan, C.M., Herman-Giddens, M.E., O’Donnell, M.E., Conaway, M., Stallings, V.A., et al.: Secondary sexual characteristics in children with cerebral palsy and moderate to severe motor impairment: a cross-sectional survey. Pediatrics 110(5), 897-902 (2002)

19. Donkervoort, M., Roebroeck, M., Wiegerink, D., van der Heijden-Maessen, H., Stam, H.: Determinants of functioning of adolescents and young adults with cerebral palsy. Disabil. Rehabil. 29(6), 453-463 (2007)

20. Palisano, R., Rosenbaum, P., Walter, S., Russell, D., Wood, E., Galuppi, B.: Development and reliability of a system to classify gross motor function in children with cerebral palsy. Dev. Med. Child. Neurol. 39(4), 214-223 (1997)

21. Wood, E., Rosenbaum, P.: The gross motor function classification system for cerebral palsy: a study of reliability and stability over time. Dev. Med. Child. Neurol. 42(5), 292-296 (2000)

22. Eliasson, A.C., Krumlinde-Sundholm, L., Rosblad, B., Beckung, E., Arner, M., Ohrvall, A.M., et al.: The Manual Ability Classification System (MACS) for children with cerebral palsy: scale development and evidence of validity and reliability. Dev. Med. Child. Neurol. 48(7), 549-554 (2006)

23. Bender, J., Hoing, M., Van Dam, A., Visser, T., Van Berlo, W.: Is revalidatie aan seks toe? Utrecht: RNG; 2005 [updated 2005; cited]; Available from: http://www.rutgersnissogroep.nl/productenendiensten/ onderzoekspublicaties/onderzoekspublicaties-1/downloadbare-publicaties-in-pdf/is-revalidatie-aan-seks-toeseksuele-problemen-van-revalidanten-en-hun-partners.pdf

24. Gijs, L., Gianotten, W., Vanwesenbeeck, I., Weijenborg, P. (eds.): Seksuologie. 2e druk ed. Bohn Stafleu van Loghum, Houten (2009)

25. Jahnsen, R., Villien, L., Stanghelle, J.K., Holm, I.: Fatigue in adults with cerebral palsy in Norway compared with the general population. Dev. Med. Child Neurol. 45(5), 296-303 (2003)

26. Bakker, F.: Rapport Seksuele gezondheid in Nederland 2009. RNG; 2009 [updated 2009; cited]; Available from: http://www.rng.nl/productenendiensten/onderzoekspublicaties/onderzoekspublicaties-1/downloadb are-publicaties-in-pdf/rapport-seksuele-gezondheid-in-nederland-2009 